\title{
Abnormal Re-epithelialization and Lung Remodeling in Idiopathic Pulmonary Fibrosis: The Role of $\Delta \mathrm{N}-\mathrm{p} 63$
}

\author{
Marco Chilosi, Venerino Poletti, Bruno Murer, Maurizio Lestani, \\ Alessandra Cancellieri, Licia Montagna, Paola Piccoli, Giulia Cangi, \\ Gianpietro Semenzato, and Claudio Doglioni
}

\author{
Department of Pathology (MC, ML, LM, PP), University of Verona, Verona, Department of Pneumology (VP), Forli \\ Hospital, Forli, Department of Pathology, Mestre Hospital, Mestre, Department of Pathology (AC), Maggiore \\ Hospital, Bologna, Department of Clinical and Experimental Medicine (GS), University of Padua, Padua, and \\ Department of Pathology (GC, CD), Belluno Hospital, Belluno, Italy
}

\begin{abstract}
SUMMARY: Products of the p63 gene, a recently described member of the p53 family, are constitutively expressed in the basal cells of human bronchi and bronchioli. The truncated isoforms of the p63 gene $(\Delta \mathrm{N}-\mathrm{p} 63$ proteins) counteract the apoptotic and cell cycle inhibitory functions of p53 after DNA damage, and this property is likely to be central in the cell renewal strategy of stratified epithelial tissues. To investigate the dysfunctional repair processes that characterize idiopathic pulmonary fibrosis/usual interstitial pneumonia (IPF/UIP), we immunohistochemically analyzed the expression of the transactivating and dominantnegative isoforms of the $\mathrm{p} 63$ gene on 16 tissue samples obtained from patients suffering from this disorder. In most IPF cases herein investigated, epithelial cells expressing $\Delta \mathrm{N}$-p63 were observed at sites of abnormal proliferation at the bronchiolo-alveolar junctions, characterized by epithelial hyperplasia, squamous metaplasia, bronchiolization, and abnormal p53 nuclear accumulation. Similar features were not observed in normal lung and in samples taken from other pulmonary diseases used as controls, including acute interstitial pneumonia, idiopathic bronchiolitis obliterans organizing pneumonia, nonspecific interstitial pneumonia, and desquamative interstitial pneumonia. On the basis of these findings, we can hypothesize a new model for UIP pathogenesis, involving a deregulated development of mesenchymal-epithelial interactions and abnormal proliferation of epithelial cells at the bronchiolo-alveolar junction after cell injury. In our view, the progressive loss of alveolar tissue and lung remodeling after injury in IPF/UIP is concomitantly produced by pneumocyte loss and alveolar collapse on one hand and by progressive bronchiolar proliferation and architectural distortion on the other. (Lab Invest 2002, 82:1335-1345).
\end{abstract}

$I$ diopathic pulmonary fibrosis (IPF) is the most common and severe form of idiopathic interstitial pneumonia (American Thoracic Society, 2000; Katzenstein and Myers, 1998; Poletti and Kitaichi, 2001). It is typically associated with the histologic features of usual interstitial pneumonia (UIP), and demonstration of the UIP pattern on a surgical lung biopsy specimen is useful for a definitive diagnosis (American Thoracic Society, 2000). A chronic inflammatory process leading to alveolar injury and deregulated extracellular matrix deposition in the lung interstitium, with eventual parenchymal remodeling and irreversible loss of respiratory functions, have been thought to account for the pathogenesis of IPF/UIP. However, many questions regarding IPF/UIP still remain unsolved in terms of etiology, pathogenesis, and natural history. Recently, the "inflammatory theory" of IPF has been challenged. New pathogenetic hypotheses have been suggested,

DOI: 10.1097/01.LAB.0000032380.82232.67

Received April 23, 2002.

This work was supported in part by Associazione Italiana per la Ricerca sul Cancro (AIRC), Milan, Italy.

Address reprint requests to: Dr. Marco Chilosi, Anatomia Patologica, Dipartimento di Patologia, Università di Verona, Policlinico G.B. Rossi,

P.le L.Scuro,37134Verona, Italy.E-mail:m.chilosi@univr.it focusing on the abnormal proliferation of fibroblasts and myofibroblasts and on their primary role in causing abnormal wound healing after multiple, microscopic epithelial injury with eventual triggering of irreversible fibrosis (Selman et al, 2001). Moreover, new evidence has been provided pointing to a major role of dysregulated regeneration of epithelial cell components in pulmonary fibrosis, influencing stromal and vascular remodeling in affected areas (Keane et al, 2001; Kolb et al, 2001; Sheppard, 2001). This change in views seems particularly intriguing because it might provide the rationale for new therapeutic approaches, aimed at contrasting fibroblast proliferation and/or inducing fibroblast apoptosis (Selman et al, 2001; Ziesche et al, 1999). Nevertheless, the centrality of fibroblasts/myofibroblasts in IPF/UIP still remains controversial and unproven. In addition, little is known about the precise nature, timing, and primary target of epithelial injury or the role of proliferative events of both the epithelial and stromal components after tissue damage.

The aim of this study was to evaluate whether derangement of cell renewal and tissue repair in lung diseases can be related to specific molecular patterns defined by abnormal expression of molecules involved in crucial pathways that regulate both cell fate and 
proliferation. The study was focused on the evaluation of the p53 pathway, searching for abnormal interactions occurring in situ between the expression of p53, its downstream effector $\mathrm{p} 21^{\text {WAF } 1}$, and p63, a recently described member of the p53 family. Our interest in this latter gene comes from the evidence that bronchial and bronchiolar basal cells constitutively express high levels of this peculiar molecule in their nuclei (Chilosi and Doglioni, 2001). At variance with the alveolar compartment whose renewal is provided by type II pneumocytes, the cell renewal of bronchial and bronchiolar compartments is highly dependent on basal cells, specialized cells that remain in close contact with basal lamina through hemidesmosomes and that are characterized by peculiar morphology and phenotype, including the expression of highmolecular weight cytokeratins 5 and 14 (Boers et al, 1998; Evans and Moller, 1991).

The p63 gene is a member of the p53 tumor suppressor gene family (Osada et al, 1998; Parsa et al, 1999; Yang et al, 1998) that plays an important role in the physiologic maintenance of different specialized epithelia (Mills et al, 1999; Yang et al, 1999). Its gene functions are heterogeneous and complex because it undergoes splicing by alternative transcription from two different promoters, producing as many as six distinct isoforms that exert potentially contrasting effects on the same molecular and cellular targets (Yang et al, 1998). Transactivating isoforms (the TA-p63 class) maintain a sequence corresponding to the transactivating domain of p53 and have in fact functions similar to p53 in inducing cell-cycle arrest (mediated by $\mathrm{p} 21^{\text {WAF1}}$ ) and apoptosis. The second class, on the other hand, includes forms lacking the $\mathrm{NH}_{2}-$ terminal domain $(\Delta \mathrm{N}-\mathrm{p} 63)$, produced when the p63 gene is transcribed from the cryptic promoter in intron 3. $\Delta \mathrm{N}$-p63 forms act as dominant-negative agents toward transactivation by p53 and p63 itself, inhibiting the activity of p53 (Yang and McKeon, 2000). When overexpressed, these molecular p63 variants can thus behave as oncogenic molecules. Accordingly, p63 gene amplification and overexpression of $\Delta \mathrm{N}-\mathrm{p} 63$ have been demonstrated in primary lung carcinoma and other malignancies (Crook et al, 2000; Hibi et al, $2000,2001)$. Further complexity is provided by the recent demonstration of mutual influences occurring between $\mathrm{p} 53$ and p63, generated by the suppressing activity of p53 on dominant negative functions of $\Delta \mathrm{N}$-p63 (Ratovitski et al, 2001). In addition, recent experimental evidence has been provided suggesting that the combined function of p63 and p73 is required for p53-dependent apoptosis in response to DNA damage (Flores et al, 2002). Having considered all these facts, we hypothesized that the p63 gene products, through interference with the p53 pathway, may exert a relevant role in the abnormal process of tissue repair and remodeling occurring in IPF/UIP and also in the increased rate of malignant transformation observed in this disease (Kawasaki et al, 2001; Matsushita et al, 1995; Mizushima and Kobayashi, 1995; Turner-Warwick et al, 1980).
Using antibodies that specifically recognize either the transactivating TA-p63 or the truncated $\Delta \mathrm{N}-\mathrm{p} 63$ isoforms (Hibi et al, 2000; Yang et al, 1998), we have investigated in situ the expression features of the p63 gene in a series of IPF/UIP lung samples. The expression of p53 and cell-cycle inhibitors p2 $1^{\text {WAF1 }}$ and p2 $7^{\mathrm{KIP} 1}$ has also been investigated on serial sections of the same tissues. As compared with other idiopathic interstitial pneumonias herein taken into account (nonspecific interstitial pneumonia [NSIP], bronchiolitis obliterans organizing pneumonia [BOOP], acute interstitial pneumonia [AIP], desquamative interstitial pneumonia [DIP]), we provide evidence that an abnormal bronchiolar proliferation takes place in IPF/UIP.

\section{Results}

\section{p63 mRNA Expression in Normal Lung}

As shown in Figure 1, both the truncated $\Delta \mathrm{N}$-p63 (line 1) and the transactivating TA-p63 (line 2) mRNA forms were expressed, as determined by RT-PCR analysis on frozen tissue samples of normal lung tissue. No signal was detected in negative controls (line 3).

\section{p63 Immunohistochemical Analysis in Normal Lung}

In all normal lung samples, nuclear p63 expression was evident in the nuclei of bronchial and bronchiolar basal cells (Fig. 2a). The expression was comparable as far as localization and intensity of immunostaining, using both the pan-p63 4A4 clone and the p40 antibody (double-positive, type I immunoreactivity pattern, corresponding to prevalent expression of truncated $\Delta \mathrm{N}$-p63 forms). The basal cells were discrete in number, rarely forming contacts with each other. No reactivity was observed in any cell throughout the alveolar compartments using either anti-p63 antibodies (type III immunoreactivity pattern), with the exception of scattered, type II pneumocytes reacting with 4A4 antibody, or p40 antibody (type II immunoreactivity pattern, corresponding to expression of TA-p63 forms).

The expression of p53 and p21 WAF1 was either absent or barely detectable in all cell types. However, p2 $7^{\mathrm{KIP} 1}$ nuclear expression was evident in most bron-

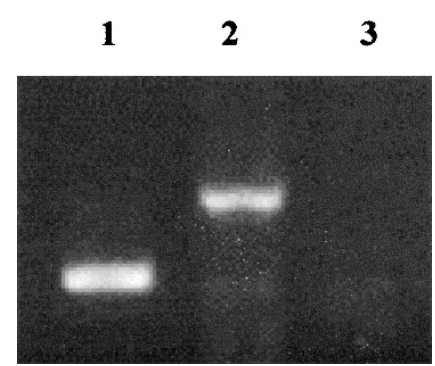

Figure 1.

Expression of p63 mRNA in normal lung. Both the truncated $\Delta \mathrm{N}$ p63 (line 1) and the transactivating TAp63 (line 2) mRNA forms were expressed, as determined by RT-PCR analysis on frozen tissue sample of normal lung tissue. No signal was detected in the negative control (line 3). 

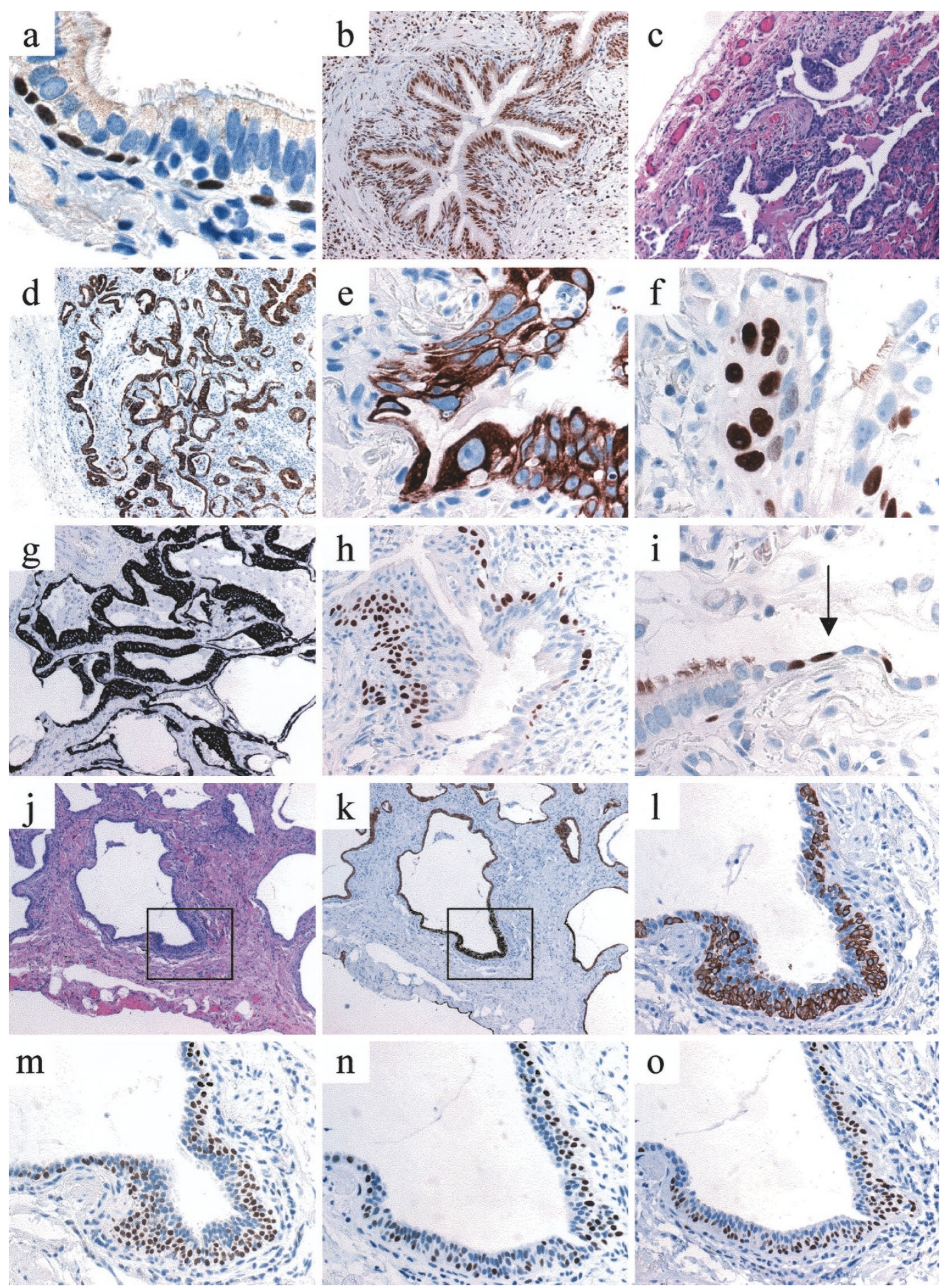

Figure 2.

a, Normal lung: expression of $p 63$ truncated isoforms is revealed in the nuclei of basal cells by immunostaining with anti- $\Delta \mathrm{N}-\mathrm{p} 63$ antibody. $\mathrm{b}$, Normal lung: nuclear expression of the cyclin-dependent kinase inhibitor $p 27^{\text {kip1 }}$ in bronchiolar epithelium. c, Idiopathic pulmonary fibrosis/usual interstitial pneumonia (IPF/UIP) Case 5 : a low-magnification view of a large portion of lung parenchyma showing bronchiolar hyperplasia with bronchioles reaching peripheral lung zones close to the pleural surface (HE). d, IPF/UIP Case 5: cytokeratin immunostaining highlights bronchiolar hyperplasia on a serial section to panel c. e, IPF/UIP Case 5: atypical cells expressing high-molecular weight cytokeratin $34 \beta E 12$ in a bronchiolar proliferative lesion. f, IPF/UIP Case 5: enlarged atypical nuclei of $\Delta \mathrm{N}$-p $63+$ basal cells in the same lesion (serial section to panel d). g, IPF/UIP Case 6: cytokeratin immunostaining highlighting the striking bronchiolar hyperplasia, with abnormalities including squamous metaplasia. h, IPF/UIP Case 6: crowding of $\Delta \mathrm{N}$-p63-expressing basal cells in a poorly modified bronchiole in the same UIP case. Note enlarged atypical nuclei on the right. i, IPF/UIP Case 2. Evidence of bronchiolization, the progressive extension of $\Delta \mathrm{N}$-p63-expressing basal cells in adjacent alveolar spaces. j, IPF/UIP Case 15: a peripheral lung portion heavily involved by tissue remodeling, with honeycomb cysts characterized by bronchiolar features (HE). $k$, IPF/UIP Case 15: a serial section immunostained for cytokeratin 8/18. I, IPF/UIP Case 15: cytokeratin 34ßE12 expression highlights basal cell hyperplasia in a serial section to panel k. The area corresponds to the rectangle included in $\mathrm{j}$ and $\mathrm{k}$. $\mathrm{m}$, IPF/UIP Case 15: the bronchiolar nature of the cyst is confirmed by nuclear expression of $\Delta \mathrm{N}$-p63 in hyperplastic basal cells. n, IPF/UIP Case 15: abnormal nuclear accumulation of p53 in hyperplastic basal cells. 0, IPF/UIP Case 15: abnormal p21 waf1 nuclear accumulation is demonstrated at the same location of $\mathrm{p} 53$ and $\Delta \mathrm{N}-\mathrm{p} 63$. 
chiolar columnar cells (Fig. 2b), with heterogeneous immunostaining in basal cells.

\section{Idiopathic Pulmonary Fibrosis Samples (IPF/UIP)}

A synthesis of the results obtained in our study can be found in Table 1 and Figures 2 and 3.

Bronchiolar Abnormalities. In most samples (14/16) the bronchiolar component appeared significantly increased in number and size, as revealed by morphology and cytokeratin immunostaining, extending peripherally toward the pleural surface (Figs. 2, c and d, and $3 a$ ). In most samples of UIP, abnormalities were found to affect bronchiolar structures and alveolobronchiolar junctions, including bronchiolar hyperplasia and distortion, squamous metaplasia, basal cell crowding, and atypia (Table 1). In a single case (Case 12), bronchiolar loss was observed, with scarred areas containing abundant remnants of smooth muscle, located near pulmonary arteries. Abnormalities involving basal cells including hyperplasia, crowding with focal formation of small nodules, enlarged nuclei, atypia, and abnormal location were poorly evident at morphologic evaluation using standard hematoxylin and eosin (HE) staining but were highlighted by p63 immunostaining (Fig. 2, f, h, and i). In fact, a highly increased number of p63-expressing cells were found in bronchioles in the large majority of UIP samples. All these positive cells were characterized by the type I immunoreactivity pattern and were then considered as $\Delta \mathrm{N}$-p63 positive. Abnormal location of $\Delta \mathrm{N}$-p63-expressing cells was particularly frequent at the bronchiolo-alveolar junctions, where superficially located positive nuclei were often observed either scattered or forming small cellular rows. $\Delta \mathrm{N}$-p63 immunostaining of superficial basal cells better visualized the distal extension of the so-called "bronchiolization," a process of migrating bronchiolar cells progressively colonizing alveolar spaces (Fig. 2i).

Honeycomb Cell Characterization. A thorough investigation was performed to define the phenotype of honeycomb lung cysts and of restructured airspaces bordered by cuboidal epithelium and entrapped in areas of consolidation and dense fibrosis. In most cases (13/16; Table 1) we observed many lesions characterized as bronchiolar by the presence of $\Delta \mathrm{N}$ p63-expressing cells. These honeycomb lesions were either lined by columnar epithelium or by large monostratified cuboidal cells (Fig. 2, j to o, and 3, d and e). The bronchiolar nature of these lesions was confirmed on serial sections by the expression of high-molecular weight cytokeratin $34 \beta \mathrm{E} 12$ and $\Delta \mathrm{N}$-p63 (Fig. 2, I and $\mathrm{m})$ and by the absence of expression of both surfactant and CC10 antigens.

Table 1. Bronchiolar Abnormalities as Detected by $\Delta \mathrm{N}-\mathrm{p} 63$ Immunostaining in IPF/UIP Cases and Control Cases, Including BOOP, AIP, NSIP, and DIP

\begin{tabular}{|c|c|c|c|c|c|c|c|c|}
\hline IPF/UIP case & $\begin{array}{c}\text { Patient } \\
\text { age/gender }\end{array}$ & $\begin{array}{c}\Delta \mathrm{N}-\mathrm{p} 63+ \\
\text { Bronchiolization }\end{array}$ & $\begin{array}{c}\Delta \mathrm{N}-\mathrm{p63+} \\
\text { Atypical } \\
\text { basal cells }\end{array}$ & Bronchiolar & $\begin{array}{c}\Delta \mathrm{N}-\mathrm{p} 63+ \\
\text { Bronchiolar } \\
\text { honeycombing h }\end{array}$ & $\begin{array}{c}\text { Alveolar } \\
\text { oneycombing }\end{array}$ & $\begin{array}{c}\text { P53+ Basal } \\
\text { cells }\end{array}$ & $\begin{array}{l}\text { Bronchiolar } \\
\text { TN + FFN }\end{array}$ \\
\hline 1 & $69 \mathrm{~F}$ & ++ & + & +++ & +++ & + & + & + \\
\hline 2 & $70 \mathrm{M}$ & ++ & ++ & + & + & + & + & + \\
\hline 3 & $50 \mathrm{M}$ & ++ & +++ & + & ++ & + & +++ & +++ \\
\hline 4 & $74 \mathrm{~F}$ & + & +++ & + & +++ & + & +++ & +++ \\
\hline 5 & $23 \mathrm{~F}$ & + & +++ & +++ & +++ & +++ & +++ & ++ \\
\hline 6 & $67 \mathrm{M}$ & +++ & +++ & +++ & +++ & ++ & +++ & +++ \\
\hline 7 & $52 \mathrm{M}$ & +++ & + & ++ & +++ & + & + & + \\
\hline 8 & $66 \mathrm{M}$ & +++ & ++ & +++ & ++ & + & ++ & ++ \\
\hline 9 & $61 \mathrm{M}$ & +++ & + & +++ & +++ & + & + & + \\
\hline 10 & $58 \mathrm{M}$ & + & - & - & + & ++ & - & + \\
\hline 11 & $51 \mathrm{M}$ & + & + & + & + & ++ & - & - \\
\hline 12 & $50 \mathrm{M}$ & - & - & - & - & + & - & - \\
\hline 13 & $45 \mathrm{M}$ & ++ & ++ & ++ & +++ & ++ & +++ & +++ \\
\hline 14 & $60 \mathrm{~F}$ & + & + & ++ & ++ & + & ++ & ++ \\
\hline 15 & $67 \mathrm{M}$ & +++ & +++ & +++ & +++ & ++ & +++ & ++ \\
\hline 16 & $60 \mathrm{~F}$ & ++ & ++ & ++ & ++ & - & ++ & ++ \\
\hline Normal lung (5) & See text & - & - & - & - & - & - & - \\
\hline BOOP [10] & $\begin{array}{c}\text { [7] M, [3] F } \\
\text { age } 60 \\
\text { (median) }\end{array}$ & - & - & - & - & - & - & $-(\mathrm{ILP}+)$ \\
\hline AIP [1] & $67 \mathrm{M}$ & - & - & - & - & - & Rare + & - \\
\hline NSIP [4] & $\begin{array}{c}58 \mathrm{M}, 52 \mathrm{M}, 58 \\
\mathrm{~F}, 69 \mathrm{~F}\end{array}$ & $-(1+)$ & - & - & - & - & - & - \\
\hline DIP [2] & 69 F, $59 \mathrm{M}$ & - & - & - & - & - & - & - \\
\hline
\end{tabular}

TN + FFN, tenascin + fibroblastic foci; ILP, intraluminal polyps; UIP, usual interstitial pneumonia; BOOP, bronchiolitis obliterans organizing pneumonia; AIP, acute interstitial pneumonia; NSIP, nonspecific interstitial pneumonia; DIP, desquamative interstitial pneumonia.

[ ] number of cases. 

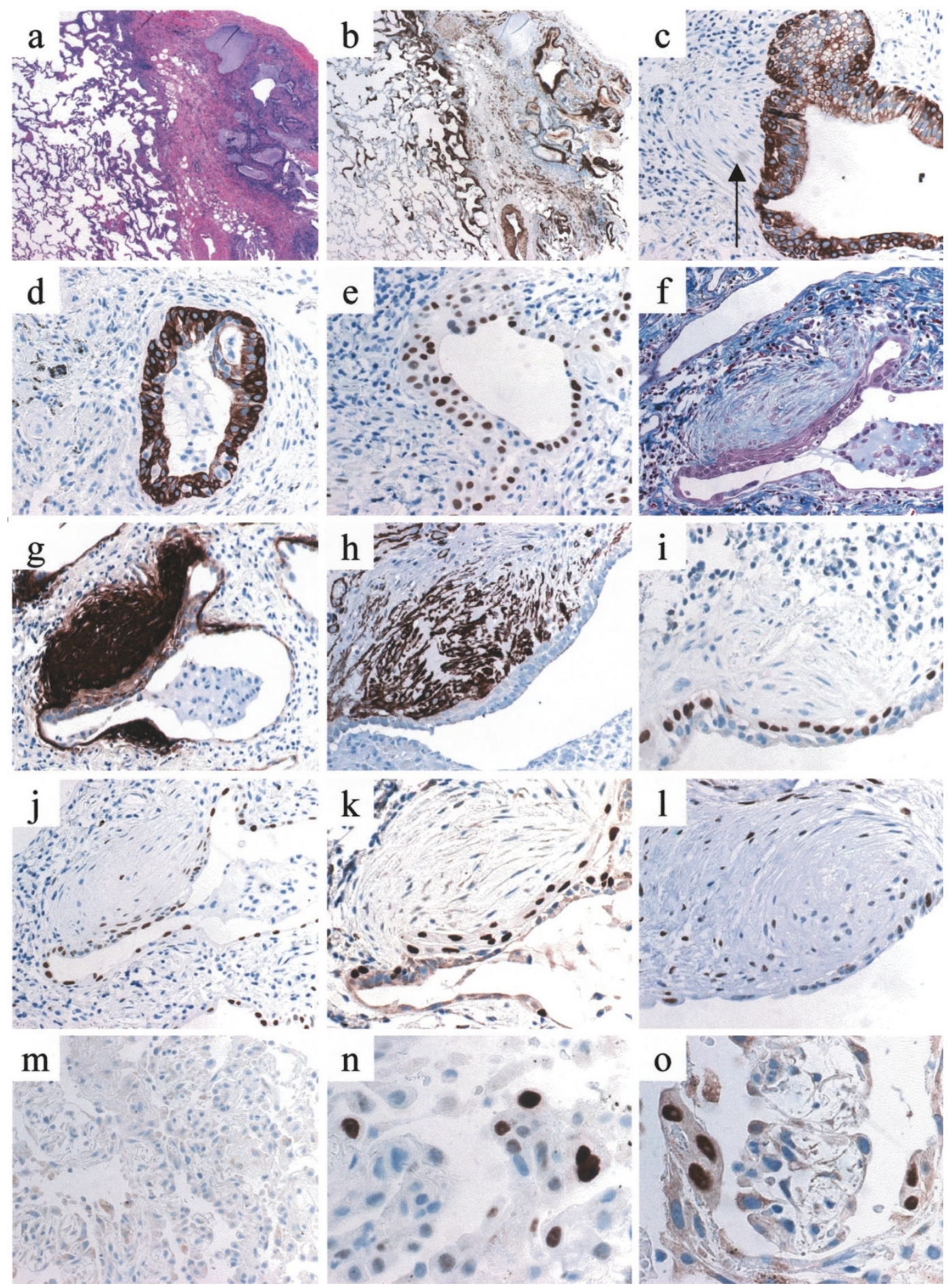

Figure 3.

a, IPF/UIP Case 13: a low-magnification view of lung showing normal or minimally involved parenchyma (left) and a large portion of tissue involved by remodeling with large honeycomb cysts reaching the subpleural zone (right) (HE). b, IPF/UIP Case 13: tenascin immunostaining on a serial section to panel a, highlighting ongoing fibrogenesis. Tenascin accumulation is mostly distributed along the boundary zone and around honeycomb cysts. C, IPF/UIP Case 13: the presence of a mural fibroblast focus (arrow) involving an hyperplastic bronchiole, as evidenced by $34 \beta E 12$ immunostaining. d, IPF/UIP Case 5: a small honeycomb cyst characterized as bronchiolar by $34 \beta \mathrm{BE} 12$ cytokeratin expression. e, IPF/UIP Case 5: the bronchiolar nature of the same lesion is confirmed by $\Delta \mathrm{N}$-p63 nuclear expression on a serial section. f, IPF/UIP Case 3: a fibroblast focus (FF) formed by spindle-shaped myofibroblasts involving a proliferative epithelial lesion (trichrome stain). g, IPF/UIP Case 3: strong expression of the extracellular matrix protein tenascin in the FF on a serial section to panel f. h, IPF/UIP Case 3: $\alpha$-smooth muscle actin $(\alpha$-SMA) expression in spindle-shaped myofibroblasts forming the same FF on a serial section. i, IPF/UIP Case 3: the abnormal cuboidal epithelium lining the same FF is characterized as bronchiolar by the presence of $\Delta \mathrm{N}-\mathrm{p} 63+$ basal cells. j, IPF/UIP Case 3: abnormal accumulation of $p 53$ in scattered epithelial cells of the same lesion (often in basal position). k, IPF/UIP Case 3: nuclear expression of p21waf1 in many epithelial cells of the same lesion. I, IPF/UIP Case 3: decreased expression of the cdk-inhibitor p2 $7^{\text {kip } 1}$ in the epithelial cells lining the FF (compare with the p2 $7^{k i p 1}$ expression of normal bronchiole, as shown in Fig. $2 b$ ). m, Acute interstitial pneumonia (AIP): $\Delta \mathrm{N}-\mathrm{p} 63$ is not expressed by hyperplastic alveolar pneumocytes. $\mathrm{n}$, AIP: a large proportion of hyperplastic and/or atypical pneumocytes express transactivating TA-p63 (type II immunoreactivity pattern; see "Materials and Methods"). 0, AIP: abnormal p53 nuclear accumulation is evident in hyperplastic pneumocytes. 
p53 Expression in Bronchiolar Lesions. When analyzed on serial sections or by double marker analysis, large proportions of $\Delta \mathrm{N}$-p63-expressing basal cells coexpressed nuclear p53 in bronchiolar lesions (Figs. $2 n$ and $3 j)$. The number of nuclei showing p53 accumulation was smaller than those expressing $\Delta \mathrm{N}-\mathrm{p} 63$, representing $20 \%$ to $80 \%$ of basal cells. Interestingly, p53 expression was demonstrated in both early and advanced lesions, with p53 + basal cells identified in bronchioles exhibiting few morphologic abnormalities and also in severely affected structures and honeycomb cysts. Similar proportions of basal cells expressed p21 WAF1, the downstream effector of p53 action. High proportions of cells forming honeycomb cysts (especially those formed by bronchiolar-type structures) showed accumulation of both p53 (Fig. 2n) and p21 ${ }^{\text {WAF1 }}$ (Fig. 20).

At variance with normal bronchiolar cells that typically expressed high levels of p27 $7^{\mathrm{KIP} 1}$ (Fig. 2b), this CDK inhibitor was heterogenously expressed in IPF/ UIP samples, where large negative segments could be demonstrated in bronchiolar lesions (Fig. 31).

Epithelium and Fibroblast Foci. To define the phenotype of the epithelial structures representing the target of ongoing injury and fibrosis, all samples were carefully searched for the presence of fibroblastic foci containing myofibroblasts. A large proportion of active fibroblastic foci detected on IPF/UIP samples by morphology and by immunostaining for tenascin and $\alpha$-smooth muscle actin ( $\alpha$-SMA) (Fig. 3, g and h) were associated with segments of atypical epithelium characterized by the bronchiolar phenotype, as defined by the expression of $\Delta \mathrm{N}-\mathrm{p} 63$ and $34 \beta \mathrm{E} 12$ cytokeratin (Fig. 3, $\mathrm{C}$ and i) and by the lack of surfactant and CC10.

Alveolar Epithelial Cells. When alveolar structures could be recognized in normal or partially affected zones of pulmonary parenchyma, both type I and type II pneumocytes were completely negative in $\Delta \mathrm{N}-\mathrm{p63}-$ immunostained preparations, whereas a proportion of hyperplastic type II cells exhibited nuclear immunoreactivity when stained with the pan-p63 4A4 antibody (type II immunoreactivity pattern). This finding was considered as evidence of increased expression of the transactivating isoforms of p63 in pneumocyte regeneration. In the same areas, alveolar pneumocytes variably expressed p53 and p21 WAF1.

\section{BOOP}

Organizing pneumonia samples were studied as controls because intraluminal fibroblastic foci are typically numerous in this usually self-limited lesion and may represent the normal wound healing model to be compared with irreversible lesions of UIP. In BOOP samples of our series, a consistent number of epithelial cells expressing TA-p63 were observed in affected alveoli, with a small proportion of hyperplastic type II pneumocytes exhibiting p53 nuclear accumulation. In addition, mural fibroblast foci covered by bronchiolar cells were absent in BOOP samples, and bronchiolar structures did not show significant basal cell abnormalities as observed in IPF/UIP (even in those samples where bronchiolar lumens were reached and distorted by inflammatory polyps).

\section{AIP}

A single surgical sample characterized by the typical histologic features of diffuse alveolar damage was available for this study. In this sample $\Delta \mathrm{N}-\mathrm{p} 63-\mathrm{ex}-$ pressing nuclei were strictly located within the basal layer of bronchiolar structures, and no morphologic or phenotypical abnormalities were documented at the bronchiolo-alveolar junctions. On the other hand, the alveoli were significantly affected, showing marked hyperplasia of type II pneumocytes that expressed enhanced nuclear levels of both p53 (Fig. 3o) and p21 WAF1. A large proportion of these pneumocytes exhibited TA-p63 expression (as defined by the type II immunoreactivity pattern on serial sections; Fig. $3, \mathrm{~m}$ and $\mathrm{n}$ ). In the alveolar interstitium, which appeared diffusely widened, many myofibroblasts were observed, strongly expressing both $\alpha$-SMA and tenascin.

\section{NSIP and DIP}

In all cases analyzed, no bronchiolar changes were observed either by morphology or p63 immunostaining. Reactivity of p53 was also limited to a few scattered cells. Fibrosis was interstitial and widespread. No abnormalities of expression could be documented for p27 $7^{\mathrm{KIP} 1}$.

\section{Discussion}

In this study we provide evidence of a previously underestimated involvement of the bronchiolar epithelium and the bronchiolo-alveolar junctions in IPF/UIP, characterized by abnormal bronchiolar proliferation. Using immunohistochemical markers we demonstrated consistent cellular and molecular abnormalities affecting the bronchiolar compartment. In particular, we focused on the expression of the $\Delta \mathrm{N}-\mathrm{p} 63$ isoforms of the p63 gene, a recently described member of the p53 family, which is constitutively expressed in basal cells and not expressed in normal alveolar pneumocytes.

Analysis of p63 is particularly informative for several reasons: first, this molecule represents an extraordinarily specific biomarker for pulmonary basal cells (Chilosi and Doglioni, 2001), a cell type involved in airway cell renewal, thus providing useful information regarding the involvement of this cell type in epithelial repair and tissue remodeling in IPF/UIP. Second, the complex mechanisms used in the expression of this peculiar gene have been proven to provide signals of paramount importance for the regulation of survival and renewal of stratified epithelia (Osada et al, 1998; Parsa et al, 1999; Yang et al, 1998), and its study could possibly clarify some aspects of the pathogenesis and natural history of IPF/UIP at the molecular level. In fact, the $\Delta \mathrm{N}$-p63 $\mathrm{N}$-terminal truncated isoforms are the main p63 isoforms expressed in many epithelia (Osada et al, 1998; Parsa et al, 1999; Pellegrini et al, 2001; Yang et al, 1998), and it is thus possible to argue 
that their physiologic role is mainly related to their p53 antagonizing functions necessary for the survival of basal (stem) cells and renewal of differentiated epithelial cells.

In this study, using $\Delta \mathrm{N}$-p63 as a marker together with other well-known pulmonary epithelial markers such as cytokeratins, CC10, and surfactant, we have highlighted specific features of IPF/UIP including basal cell hyperplasia and atypia as well as the involvement of $\Delta \mathrm{N}$-p63-expressing cells in progressive alveolar colonization and honeycomb formation. None of these features were detected in samples of other diffuse lung diseases such as BOOP, NSIP, or AIP.

Another relevant finding of this study is the demonstration of a direct and recurrent bronchiolar injury, as documented in both early and advanced lesions by the nuclear accumulation of p53 and by the presence of fibroblast foci covered by segments of abnormal epithelium recognized as bronchiolar by immunophenotyping. This observation is at variance with previous observations (Paakko et al, 2000) and suggests that bronchiolo-alveolar junctions represent a relevant and specific target of injury in IPF/UIP. In fact, in other pulmonary diseases such as AIP and BOOP in our series, p53 accumulation was restricted to the alveolar compartment and bronchiolar basal cells did not show immunophenotypical abnormalities. These observations are consistent with a previous study on IPF demonstrating accumulation of $\mathrm{p} 53$ and p21WAF1 in alveolar and bronchiolar cells corresponding to apoptotic activation as revealed by TdT-mediated dUTP nick-end labeling analysis (Kuwano et al, 1996). Accumulation of p53 in affected nuclei is likely to be considered a common consequence of the triggering of the p53 pathway by genotoxic signals, oxygen compounds, or biochemical signals. At the alveolar level, when the injury is repetitive as in IPF/UIP, the overexpression of p53 can likely trigger cell cycle arrest and induction of apoptosis, ultimately leading to progressive alveolar loss. As suggested by our results, reinforcement of antiproliferative and apoptotic signals in IPF/UIP, BOOP, AIP, and also in normal lung could be provided by the expression of transactivating TA-p63 isoforms. In fact, in all these conditions, we were able to demonstrate a type II p63immunoreactivity pattern in hyperplastic alveolar epithelium.

On the other hand, we can argue that in UIP the expression of the $\Delta \mathrm{N}$-p63 isoforms in basal cells (see $\Delta \mathrm{N}$-p63 immunostaining in Figs. 2 and 3) can counteract p53 activity, thus providing an excellent proliferative setting to bronchiolar cells. The occurrence of deranged cell-cycle regulation in UIP is confirmed by the abnormally low expression in bronchiolar lesions of $\mathrm{p} 27^{\mathrm{KIP} 1}$, a potent and universal CDK inhibitor (Polyak et al, 1994), and the concomitant overexpression of p21WAF1, presumably triggered by p53 in response to stress. This latter inhibitor can also promote the irreversible commitment to differentiation of epithelial stem cells, restricting their self-renewal potential (Dotto, 2000). In IPF, bronchiolar cells are then characterized by a unique condition in which contrast- ing proliferative, apoptotic, and differentiation signals are simultaneously provided. Further studies are needed to investigate the possible role of this peculiar condition on the abnormal production of fibrogenic signals, such as platelet-derived growth factor, transforming growth factor- $\beta$, and IGF-I by bronchiolar cells in IPF/UIP (Antoniades et al, 1990; Khalil et al, 1991; Uh et al, 1998).

A final issue that needs to be taken into account is the possible role of $\Delta \mathrm{N}$-p63 in the development of lung cancer in IPF/UIP (Kawasaki et al, 2001; Matsushita et al, 1995; Turner-Warwick et al, 1980). Inactivation of the p53 function because of point mutations has been considered central to this transformation (Hojo et al, 1998). Nevertheless, nuclear accumulation of p53 and expression of molecules induced after DNA damage, such as p21 WAF1 or GADD45, has been also demonstrated in a variety of pulmonary diseases other than IPF/UIP in which epithelial injury occurs, but increased cancer development is not a common feature. These conditions include diffuse alveolar damage, BOOP (as demonstrated in this study), collagen lung disease, and experimental conditions such as acute immune complex alveolitis or after bleomycin administration (Guinee et al, 1996; Kaminski et al, 2000; Kunitake et al, 1998; Kuwano et al, 1996, 1997; Okudela et al, 1999). According to our findings it is possible to speculate that at variance with all these conditions, IPF/UIP is characterized by the occurrence of p53 abnormalities in basal cells, in concomitance with $\Delta \mathrm{N}$-p63 constitutive expression. It is thus possible to argue that $\Delta \mathrm{N}$-p63 in IPF/UIP can contribute to the proliferative dysregulation of bronchiolar cells by counteracting the diverse functions of wild-type p53 in basal cells, thus inducing unchecked survival of abnormal clones, the emergence of genetic alterations, and the eventual development of malignancy (Hojo et al, 1998; Vassilakis et al, 2000). This could be particularly true for $\Delta \mathrm{N}$-p63-expressing cells, which become abnormally located in a nonbasal (superficial) position, as those described in our study in honeycomb cysts and bronchiolization. In fact, these cells can represent exceedingly exposed targets for exogenous mutagens (eg, in smoking patients), with a further increased risk of malignant transformation. In normal bronchial and bronchiolar basal cells, the hidden basal position could represent a means to avoid contact with potentially noxious agents, including tobacco smoke, transported by respiratory gases. Accordingly, the incidence of peripheral carcinoma is significantly increased in IPF/UIP (Hironaka and Fukayama, 1999), including squamous carcinoma (Kawasaki et al, 2001), a cancer type that can be considered as typically derived from the basal cell transformation and characterized by p63 gene amplification (Hibi et al, 2000, 2001).

In conclusion, we can hypothesize that in IPF/UIP a complex scenario occurs, in which the expression of both p53 and its $\Delta \mathrm{N}-\mathrm{p} 63$ antagonist in the same basal cells might provide contrasting stimuli for apoptotic regulation and cell cycle control, eventually causing 
deranged tissue renewal at the bronchiolo-alveolar junction with exaggerated bronchiolar proliferation and progressive alveolar colonization. In this view, a crucial feature of IPF/UIP is represented by the repetitive injury to the alveolar and "junctional" zones, triggering a differential re-epithelialization of bronchiolar and alveolar components as a result of their divergent strategies for cell renewal.

All these findings, taken together, can provide new pieces in the pathogenic puzzle of IPF/UIP, suggesting a new model. The pathogenesis of IPF/UIP has been the matter of many studies, and several different, not mutually exclusive, schemes have been proposed (Mason et al, 1999). In particular, the previous, generally accepted models were focused on the progressive loss of alveolar tissue after injury, with eventual parenchymal remodeling (Fukuda et al, 1995; Katzenstein and Myers, 1998). In our view this model is correct, but not complete, because it does not account for the evident bronchiolar abnormalities characterizing UIP samples and the central role of bronchiolo-alveolar junctions as peculiar targets of injury in IPF/UIP as described in this study.

On the basis of the observed abnormalities and proliferative features occurring in epithelial lesions characterized by bronchiolar phenotype (including $\Delta \mathrm{N}$-p63 expression), we hypothesize that the severe parenchymal remodeling is concomitantly produced by pneumocyte death and alveolar collapse on one hand and the progressive bronchiolar proliferation with overgrowing airways extending distally toward the pleural surface on the other. The unbalanced signals produced by this overgrowing bronchiolartype epithelial tissue in the absence of counterbalancing signals from alveolar epithelium could contribute to the production of abnormal mesenchymal components, including collagen and smooth muscle fibers. In fact, because the mechanisms of cell renewal used by bronchioles and alveoli are different, it is possible to argue that these compartments should heterogenously respond to injury with their diversified repair mechanisms. An interesting comparison can be made between the bronchiolo-alveolar junctions and squamocolumnar junctions of the gastroesophageal tract as well as the cervical transition zone. In these tissues, in fact, two epithelial components characterized by different renewal strategies (one based on the presence of basal cells expressing $\Delta \mathrm{N}-\mathrm{p} 63$ ) are joined together in transitional regions characterized by increased metaplastic and neoplastic transformation potential (Glickman et al, 2001; Kurita and Cunha, 2001; Quade et al, 2001). A possible role of $\Delta \mathrm{N}$-p63 isoform expression in the development of lung cancer in IPF/UIP is also emphasized and needs further evaluation.

\section{Materials and Methods}

\section{Study Population}

The study group consisted of 16 previously untreated patients with clinical, radiographic (chest radiograph and high-resolution computed tomography), physiologic, and bronchoalveolar lavage findings consistent with the diagnosis of IPF. Histologic examination of surgical lung biopsy specimens revealed all the major features of UIP, according to the recently defined criteria (American Thoracic Society, 2000). In particular, heterogeneous appearance with alternating areas of normal lung were demonstrated, together with patchy interstitial inflammation, fibrosis, and honeycomb changes (American Thoracic Society, 2000; Katzenstein and Myers, 1998). Five samples of normal lung (fragments of unaffected tissue from patients submitted to large excisions for lung carcinoma), 10 samples from patients with BOOP, 4 samples of NSIP, 1 sample of AIP, and 2 samples of DIP were analyzed as controls (Table 1$)$.

\section{RNA Extraction and RT-PCR for p63}

A previously described procedure was followed (Barbareschi et al, 2001) for RNA extraction and RT-PCR analysis of normal lung samples. Briefly, frozen normal samples of lung tissue were ground using a MikroDismembrator (B. Braun, Melsungen, Germany), and RNA was extracted using a guanidine isothiocyanate protocol (TRIzol Reagent, GIBCO BRL, Life Technologies, Gaithersburg, Maryland). After DNAse treatment, equal amounts of total RNA $(1 \mu \mathrm{g})$ were reverse transcribed into CDNA using random primers and Superscript First-Strand Synthesis System (GIBCO BRL, Life Technologies) according to the manufacturer's instructions. The human Gs $\alpha$ gene was used as endogenous control. PCR for $\mathrm{p} 63$ isoforms and Gs $\alpha$ was performed in a $25-\mu$ reaction mixture containing DNA template, PCR buffer (50 mм KCl, $10 \mathrm{~mm}$ Tris- $\mathrm{HCl}, \mathrm{pH} 8.3), 1.5 \mathrm{~mm}$ $\mathrm{MgCl}_{2}, 200 \mathrm{~mm}$ of each dNTP, $0.4 \mathrm{~mm}$ of each primer (human p63 TA upstream primer 5'-ATGTCCCAGAGCACACAG-3', downstream primer 5'-AGCTCATGGTTGGGGCAC-3'; human p63 $\triangle \mathrm{N}$-upstream primer 5'-CAGACTCAATTTAGTGAG-3', downstream primer 5'-AGCTCATGGTTGGGGCAC-3'; human Gs $\alpha$ upstream primer 5'-GTGATCAAGCAGGCTGACTAT-3', downstream primer 5'-GCTGCTGGCCACCACGAAGATGAT-3'), and 0.5 U TaKaRa TaqDNA polymerase (Takara Shuzo Company, Ltd., Japan). PCR was performed for 40 cycles consisting of $95^{\circ} \mathrm{C}$ for 30 seconds, $60^{\circ} \mathrm{C}$ for 30 seconds, and $72^{\circ} \mathrm{C}$ for 1 minute. The resulting amplification products were then analyzed by agarose gel electrophoresis. Fresh-frozen lung samples of patients with UIP were not available for RT-PCR studies.

\section{Immunohistochemical Staining and Antibodies}

Lung tissue specimens were fixed in $4 \%$ buffered formaldehyde for at least 24 hours and then embedded in paraffin. Three- to $4-\mu \mathrm{m}$-thick sections were cut and mounted on adhesive-treated glass slides, paraffin was removed, and slides were rehydrated with descending concentrations of ethanol. Sections were treated for antigen retrieval and immunostaining as previously described (Chilosi et al, 1993). Briefly, sections were immersed in $0.01 \mathrm{~m}$ citrate buffer $(\mathrm{pH} 6)$ 
and microwaved for 30 minutes at $750 \mathrm{~W}$, then kept for 15 minutes at room temperature before further PBS washing and immunostaining performed using a sensitive avidin-streptavidin-peroxidase technique (BioGenex, San Ramon, California). All samples were processed using a semiautomated cell staining system (Optimax; BioGenex) and standardized procedures.

\section{Antibodies}

A panel of antibodies was selected to thoroughly investigate the molecular network regulating epithelial cell renewal after injury. We thus analyzed consecutive sections of all cases of UIP and controls of our series with the following: pan-p63 mAb (mAb clone 4A4, IgG2a; Santa Cruz Biotechnology, Santa Cruz, California), raised against amino acids 1 to 205 of the p63 gene, reacting broadly with all known variants of human p63; p40 antibody (Oncogene Research Products, Boston, Massachusetts), a polyclonal rabbit antiserum generated by immunization with a peptide corresponding to amino acids 5 to 17 of human p63 gene and recognizing the truncated $\Delta \mathrm{N}$-p63 isoforms lacking the transactivating domain and acting in a dominant-negative fashion on p53 function (Hibi et al, 2000); p53-specific mAb (clone DO-1; Dako, Glostrup, Denmark); mAb recognizing P21 WAF1 (clone SX118; Dako); and mAb recognizing p27 $7^{\mathrm{KIP} 1}$ (KIP-1, 1:1000; Transduction laboratories, Lexington, Kentucky).

To describe more precisely the complex distribution of p63 isoforms in a given cell population, we defined four immunoreactivity patterns: type I pattern, corresponding to prevalence of truncated $\Delta \mathrm{N}-\mathrm{p} 63$ isoforms, was assigned to cell populations reacting with both 4A4 and p40 antibodies at the same intensity; type II, corresponding to transactivating TA-p63 expression, was assigned to cell populations reacting with $4 \mathrm{~A} 4$ antibody but negative on serial sections with the p40 antibody; type III, double negative, corresponded to cell populations not expressing p63 at the level of sensitivity of the immunohistochemical technique. As expected, type IV immunoreactivity with p40 antibody alone was never encountered.

To better define the nature and differentiation level of the epithelial and mesenchymal cells involved in the different pulmonary lesions, we also used antibodies recognizing different relevant markers: low-molecular weight cytokeratin 8/18/19 (clone 5D3; BioGenex); $34 \beta \mathrm{E} 12$ clone (Dako) recognizing high-molecular weight cytokeratins; urine protein 1 , a rabbit antibody (Dako) recognizing CC10 antigen in Clara cells; surfactant $\mathrm{mAb}$ (clone PE-10; Dako) recognizing surfactant; $1 \mathrm{~A} 4 \mathrm{mAb}$ (Dako) recognizing $\alpha$-SMA (no antigen retrieval); and TN2 mAb (Dako) recognizing tenascin, used to better evaluate and quantitate the presence of myofibroblasts and fibroblastic foci (Chilosi et al, 1993; Kuhn and Mason, 1995). Only nuclear staining was interpreted as positive for p63, $\Delta \mathrm{N}-\mathrm{p} 63, \mathrm{p} 53$, $\mathrm{p} 21^{\mathrm{WAF} 1}$, and $\mathrm{p} 27^{\mathrm{KIP} 1}$. The expression of these molecules was scored by evaluating the intensity of each immunostaining, compared with internal positive and negative control cells, and by counting the percentage of positive nuclei in representative high-magnification microscopic fields. Different histologic features were highlighted by $\Delta \mathrm{N}$-p63 immunostaining, and a score was given based on the frequency ( - absent; + present; ++ frequent; +++ very frequent). These features included alveolar bronchiolization (defined by the presence of $\Delta \mathrm{N}$-p63 nuclei bordering alveolar spaces), atypical basal cells $(\Delta \mathrm{N}-\mathrm{p} 63+$ basal cells characterized by abnormally large nuclei), bronchiolar hyperplasia, and honeycombing (bronchiolar immunophenotype: $\Delta \mathrm{N}-\mathrm{p} 63+, 34 \beta \mathrm{E} 12+, \mathrm{CC} 10$ negative, surfactant negative). The comparative expression of different molecules was evaluated on serial sections and, when necessary, with double-marker analysis, performed as previously described (Chilosi et al, 1998).

\section{References}

American Thoracic Society (2000). Idiopathic pulmonary fibrosis: Diagnosis and treatment. International consensus statement. American Thoracic Society (ATS) and the European Respiratory Society (ERS). Am J Respir Crit Care Med 161:646-664.

Antoniades HN, Bravo MA, Avila RE, Galanopoulos T, Neville-Golden J, Maxwell M, and Selman M (1990). Plateletderived growth factor in idiopathic pulmonary fibrosis. J Clin Invest 86:1055-1064.

Barbareschi M, Pecciarini L, Cangi MG, Macri E, Rizzo A, Viale G, and Doglioni C (2001). p63, a p53 homologue, is a selective nuclear marker of myoepithelial cells of the human breast. Am J Surg Pathol 25:1054-1060.

Boers JE, Ambergen AW, and Thunnissen FB (1998). Number and proliferation of basal and parabasal cells in normal human airway epithelium. Am J Respir Crit Care Med 157: 2000-2006.

Chilosi M and Doglioni C (2001). Constitutive p63 expression in airway basal cells: A molecular target in diffuse lung diseases. Sarcoidosis Vasc Diffuse Lung Dis 18:23-26.

Chilosi M, Lestani M, Benedetti A, Montagna L, Pedron S, Scarpa A, Menestrina F, Hirohashi S, Pizzolo G, and Semenzato $G$ (1993). Constitutive expression of tenascin in $\mathrm{T}$-dependent zones of human lymphoid tissues. Am J Pathol 143:1348-1355.

Chilosi M, Piazzola E, Lestani M, Benedetti A, Guasparri I, Granchelli G, Aldovini D, Leonardi E, Pizzolo G, Doglioni C, Menestrina F, and Mariuzzi GM (1998). Differential expression of p57kip2, a maternally imprinted cdk inhibitor, in normal human placenta and gestational trophoblastic disease. Lab Invest 78:269-276.

Crook T, Nicholls JM, Brooks L, O'Nions J, and Allday MJ (2000). High level expression of DN-p63: A mechanism for the inactivation of p53 in undifferentiated nasopharyngeal carcinoma (NPC)? Oncogene 19:3439-3444.

Dotto GP (2000). p21(WAF1/Cip1): More than a break to the cell cycle? Biochim Biophys Acta 1471:M43-M56.

Evans MJ and Moller PC (1991). Biology of airway basal cells. Exp Lung Res 17:513-531.

Flores ER, Tsai KY, Crowley D, Sengupta S, Yang A, McKeon $F$, and Jacks T (2002). p63 and p73 are required for p53- 
dependent apoptosis in response to DNA damage. Nature 416:560-564.

Fukuda Y, Basset F, Ferrans VJ, and Yamanaka N (1995). Significance of early intra-alveolar fibrotic lesions and integrin expression in lung biopsy specimens from patients with idiopathic pulmonary fibrosis. Hum Pathol 26:53-61.

Glickman JN, Yang A, Shahsafaei A, McKeon F, and Odze $\mathrm{RD}$ (2001). Expression of p53-related protein p63 in the gastrointestinal tract and in esophageal metaplastic and neoplastic disorders. Hum Pathol 32:1157-1165.

Guinee D Jr, Fleming M, Hayashi T, Woodward M, Zhang J, Walls J, Koss M, Ferrans V, and Travis W (1996). Association of p53 and WAF1 expression with apoptosis in diffuse alveolar damage. Am J Pathol 149:531-538.

Hibi K, Nakayama H, Taguchi M, Kasai Y, Ito K, Akiyama S, and Nakao A (2001). AIS overexpression in advanced esophageal cancer. Clin Cancer Res 7:469-472.

Hibi K, Trink B, Patturajan M, Westra WH, Caballero OL, Hill DE, Ratovitski EA, Jen J, and Sidransky D (2000). AIS is an oncogene amplified in squamous cell carcinoma. Proc Natl Acad Sci USA 97:5462-5467.

Hironaka M and Fukayama M (1999). Pulmonary fibrosis and lung carcinoma: A comparative study of metaplastic epithelia in honeycombed areas of usual interstitial pneumonia with or without lung carcinoma. Pathol Int 49:1060-1066.

Hojo S, Fujita J, Yamadori I, Kamei T, Yoshinouchi T, Ohtsuki Y, Okada H, Bandoh S, Yamaji Y, Takahara J, Fukui T, and Kinoshita M (1998). Heterogeneous point mutations of the p53 gene in pulmonary fibrosis. Eur Respir J 12:1404-1408.

Kaminski N, Allard JD, Pittet JF, Zuo F, Griffiths MJ, Morris D, Huang X, Sheppard D, and Heller RA (2000). Global analysis of gene expression in pulmonary fibrosis reveals distinct programs regulating lung inflammation and fibrosis. Proc Natl Acad Sci USA 97:1778-1783.

Katzenstein AL and Myers JL (1998). Idiopathic pulmonary fibrosis: Clinical relevance of pathologic classification. Am J Respir Crit Care Med 157:1301-1315.

Kawasaki H, Nagai K, Yokose T, Yoshida J, Nishimura M, Takahashi K, Suzuki K, Kakinuma R, and Nishiwaki Y (2001). Clinicopathological characteristics of surgically resected lung cancer associated with idiopathic pulmonary fibrosis. J Surg Oncol 76:53-57.

Keane MP, Belperio JA, Burdick MD, Lynch JP, Fishbein MC, and Strieter RM (2001). ENA-78 is an important angiogenic factor in idiopathic pulmonary fibrosis. Am J Respir Crit Care Med 164:2239-2242.

Khalil N, O'Connor RN, Unruh HW, Warren PW, Flanders KC, Kemp A, Bereznay OH, and Greenberg AH (1991). Increased production and immunohistochemical localization of transforming growth factor-beta in idiopathic pulmonary fibrosis. Am J Respir Cell Mol Biol 5:155-162.

Kolb M, Margetts PJ, Anthony DC, Pitossi F, and Gauldie J (2001). Transient expression of IL-1 beta induces acute lung injury and chronic repair leading to pulmonary fibrosis. J Clin Invest 107:1529-1536.

Kuhn C and Mason RJ (1995). Immunolocalization of SPARC, tenascin, and thrombospondin in pulmonary fibrosis. Am $\mathrm{J}$ Pathol 147:1759-1769.

Kunitake R, Kuwano K, Miyazaki H, Kawasaki M, Hagimoto N, Fujita M, Kaneko Y, and Hara N (1998). Expression of p53, p21 (Waf1/Cip1/Sdi1) and Fas antigen in collagen vascular and granulomatous lung diseases. Eur Respir J 12:920-925.

Kurita T and Cunha GR (2001). Roles of p63 in differentiation of Mullerian duct epithelial cells. Ann NY Acad Sci 948:9-12.

Kuwano K, Hagimoto N, Nomoto Y, Kawasaki M, Kunitake R, Fujita M, Miyazaki H, and Hara N (1997). p53 and p21 (Waf1/Cip1) mRNA expression associated with DNA damage and repair in acute immune complex alveolitis in mice. Lab Invest 76:161-169.

Kuwano K, Kunitake R, Kawasaki M, Nomoto Y, Hagimoto N, Nakanishi Y, and Hara N (1996). p21Waf1/Cip1/Sdi1 and p53 expression in association with DNA strand breaks in idiopathic pulmonary fibrosis. Am J Respir Crit Care Med 154: 477-483.

Mason RJ, Schwarz MI, Hunninghake GW, and Musson RA (1999). NHLBI Workshop Summary. Pharmacological therapy for idiopathic pulmonary fibrosis: Past, present, and future. Am J Respir Crit Care Med 160:1771-1777.

Matsushita H, Tanaka S, Saiki Y, Hara M, Nakata K, Tanimura S, and Banba J (1995). Lung cancer associated with usual interstitial pneumonia. Pathol Int 45:925-932.

Mills AA, Zheng B, Wang XJ, Vogel H, Roop DR, and Bradley A (1999). p63 is a p53 homologue required for limb and epidermal morphogenesis. Nature 398:708-713.

Mizushima Y and Kobayashi M (1995). Clinical characteristics of synchronous multiple lung cancer associated with idiopathic pulmonary fibrosis: A review of Japanese cases. Chest 108:1272-1277.

Okudela K, Ito T, Mitsui H, Hayashi H, Udaka N, Kanisawa M, and Kitamura $\mathrm{H}$ (1999). The role of p53 in bleomycin-induced DNA damage in the lung: A comparative study with the small intestine. Am J Pathol 155:1341-1351.

Osada M, Ohba M, Kawahara C, Ishioka C, Kanamaru R, Katoh I, Ikawa Y, Nimura Y, Nakagawara A, Obinata M, and Ikawa $S$ (1998). Cloning and functional analysis of human $\mathrm{p} 51$, which structurally and functionally resembles $\mathrm{p} 53$. Nature Med 4:839-843.

Paakko P, Kaarteenaho-Wiik R, Pollanen R, and Soini $Y$ (2000). Tenascin mRNA expression at the foci of recent injury in usual interstitial pneumonia. Am J Respir Crit Care Med 161:967-972.

Parsa R, Yang A, McKeon F, and Green H (1999). Association of $p 63$ with proliferative potential in normal and neoplastic human keratinocytes. J Invest Dermatol 113:1099-1105.

Pellegrini G, Dellambra E, Golisano O, Martinelli E, Fantozzi I, Bondanza S, Ponzin D, McKeon F, and De Luca M (2001). p63 identifies keratinocyte stem cells. Proc Natl Acad Sci USA 98:3156-3161.

Poletti V and Kitaichi M (2001). Facts and controversies in the classification of idiopathic interstitial pneumonias. Sarcoidosis Vasc Diffuse Lung Dis 17:229-238.

Polyak K, Kato JY, Solomon MJ, Sherr CJ, Massague J, Roberts JM, and Koff A (1994). p2 $7^{\text {KIP1 }}$, a cyclin-Cdk inhibitor, links transforming growth factor-beta and contact inhibition to cell cycle arrest. Genes Dev 8:9-22.

Quade BJ, Yang A, Wang Y, Sun D, Park J, Sheets EE, Cviko A, Federschneider JM, Peters R, McKeon FD, and Crum CP (2001). Expression of the p53 homologue p63 in early cervical neoplasia. Gynecol Oncol 80:24-29. 
Ratovitski EA, Patturajan M, Hibi K, Trink B, Yamaguchi K, and Sidransky D (2001). p53 associates with and targets delta Np63 into a protein degradation pathway. Proc Natl Acad Sci USA 98:1817-1822.

Selman M, King TE Jr, and Pardo A (2001). Idiopathic pulmonary fibrosis: Prevailing and evolving hypotheses about its pathogenesis and implications for therapy. Ann Intern Med 134:136-151.

Sheppard D (2001). Pulmonary fibrosis: A cellular overreaction or a failure of communication? J Clin Invest 107:15011502.

Turner-Warwick M, Lebowitz M, Burrows B, and Johnson A (1980). Cryptogenic fibrosing alveolitis and lung cancer. Thorax 35:496-499.

Uh ST, Inoue Y, King TE Jr, Chan ED, Newman LS, and Riches DW (1998). Morphometric analysis of insulin-like growth factor-I localization in lung tissues of patients with idiopathic pulmonary fibrosis. Am J Respir Crit Care Med 158:1626-1635.

Vassilakis DA, Sourvinos G, Spandidos DA, Siafakas NM, and Bouros D (2000). Frequent genetic alterations at the microsatellite level in cytologic sputum samples of patients with idiopathic pulmonary fibrosis. Am J Respir Crit Care Med 162:1115-1119.
Yang A, Kaghad M, Wang Y, Gillett E, Fleming MD, Dotsch V, Andrews NC, Caput D, and McKeon F (1998). p63, a p53 homolog at 3q27-29, encodes multiple products with transactivating, death-inducing, and dominant-negative activities. Mol Cell 2:305-316.

Yang $A$ and McKeon F (2000). P63 and P73: P53 mimics, menaces and more. Nat Rev Mol Cell Biol 1:199-207.

Yang A, Schweitzer R, Sun D, Kaghad M, Walker N, Bronson RT, Tabin C, Sharpe A, Caput D, Crum C, and McKeon F (1999). p63 is essential for regenerative proliferation in limb, craniofacial and epithelial development. Nature 398:714718.

Ziesche R, Hofbauer E, Wittmann K, Petkov V, and Block LH (1999). A preliminary study of long-term treatment with interferon gamma- $1 \beta$ and low-dose prednisolone in patients with idiopathic pulmonary fibrosis. N Engl J Med 341:12641269. 